\title{
Maternal neutralizing antibodies against a CRFOI_AE primary isolate are associated with a low rate of intrapartum HIV-I transmission in Thailand
}

\author{
Suzie Thenin*1, Tanawan Samleerat ${ }^{1,2}$, Gonzague Jourdain ${ }^{3,4}$, Nicole Ngo- \\ Giang-Huong ${ }^{3,4}$, Alain Moreau ${ }^{1}$, Pranee Leechanachai ${ }^{2}$, Marc Lallemand ${ }^{3,4}$, \\ Françis Barin ${ }^{1}$ and Martine Braibant ${ }^{1}$
}

Address: ${ }^{1}$ Université François Rabelais, Tours, France, ${ }^{2}$ Chiang Mai University, Chiang Mai, Thailand, ${ }^{3}$ Harvard School of Public Health, Boston, USA and ${ }^{4}$ Institut de Recherche pour le Développement, Chiang Mai, Thailand

* Corresponding author

\begin{abstract}
from Fifth Dominique Dormont International Conference. Mother-to-child transmitted viral diseases: from transmission to children care Paris, France. 26-28 March 2009

Published: 22 July 2009

Retrovirology 2009, 6(SuppI I):P5 doi:I0.II86/I742-4690-6-SI-P5
\end{abstract}

This abstract is available from: http://www.retrovirology.com/content/6/SI/P5

(c) 2009 Thenin et al; licensee BioMed Central Ltd.

\section{Background}

Mother-to-child transmission (MTCT) of HIV-1 provides a model for studying the role of passively acquired antibodies in preventing infection. We previously hypothesized that broadly neutralizing heterologous antibodies (NAbs) would protect babies against intrapartum (IP) transmission. We measured NAb titers against primary isolates of various clades in sera from pregnant Thai women, and identified an association between higher titers of Nabs against a CRF01_AE primary isolate, MBA, and lower rates of IP transmission. Here, we extended our previous study using three CRF01_AE strains in a different Thai population, to confirm the association previously observed. We also investigated the molecular characteristics of the MBA envelope glycoprotein (Env) that might explain this association.

\section{Methods}

We measured and compared the titers of NAbs against six primary isolates ( 3 CRF01_AE and 3 clade B strains) in sera from 45 transmitting $(\mathrm{T})$ and 45 nontransmitting (NT) Thai mothers matched for baseline viral load and duration of zidovudine prophylaxis, the two main independent factors associated with MTCT. We cloned and sequenced the env gene of the three CRF01_AE strains and compared the neutralization profiles by mothers' sera of pseudotyped viruses expressing wild type or chimeric Env proteins.

\section{Results}

Among CRF01_AE strains, MBA was more resistant to neutralization than the two other strains, LEA and C1712. The three clade B strains displayed similar neutralization profiles. We did not find an association between NAbs and MTCT for the three B strains or for LEA and C1712. In contrast, higher levels of NAbs against MBA were significantly associated with lower rates of IP transmission. The Env of this strain showed an unusually long V2 domain of 63 amino acids including six potential N-linked glycosylation sites. Using pseudotyped viruses expressing either MBA or LEA wild-type Env or a chimeric Env containing the V2 domain of MBA in an LEA Env backbone, we showed that the extended V2 domain contributed to the higher level of resistance to neutralization by mothers' sera in this strain.

\section{Conclusion}

This study confirms that higher titers of maternal NAbs against a CRF01_AE primary isolate, MBA, are associated with a lower IP risk of HIV-1 transmission in Thailand, and that the V2 domain of gp120 seems to have a major role in the neutralization process. We suggest that some 
primary isolates may be useful indicators for identifying protective antibodies.

Publish with Bio Med Central and every scientist can read your work free of charge

"BioMed Central will be the most significant development for disseminating the results of biomedical research in our lifetime. " Sir Paul Nurse, Cancer Research UK

Your research papers will be:

- available free of charge to the entire biomedical community

- peer reviewed and published immediately upon acceptance

- cited in PubMed and archived on PubMed Central

- yours - you keep the copyright 